\title{
Thermal Stability of Low-Temperature-Carburized Austenitic Stainless Steel
}

\author{
Jun Wang, ${ }^{1,2}$ Zhen Li (co-first author), ${ }^{1}$ Danqi Wang, ${ }^{3}$ Shaoyu Qiu ${ }^{4}$, Frank Ernst ${ }^{1 *}$ \\ ${ }^{1}$ Department of Materials Science and Engineering, Case Western Reserve University, \\ Cleveland, $\mathrm{OH}$ 44106-7204, USA. \\ ${ }^{2}$ School of Manufacturing Science and Engineering, Sichuan University, \\ Chengdu, 610065, PR China. \\ ${ }^{3}$ Swagelok Center for Surface Analysis of Materials, Case Western Reserve University \\ Cleveland, $\mathrm{OH}$ 44106-7204, USA. \\ ${ }^{4}$ The Key Nuclear Fuel and Nuclear Materials Laboratory of China, Nuclear Power Institute of China, \\ Chengdu, 610041, PR China.
}

\section{Abstract}

To study the thermal stability of the "case" (hard layer) that forms on AISI-316L austenitic stainless steel by low-temperature carburization, we exposed carburized specimens to temperatures between $573 \mathrm{~K}$ and $648 \mathrm{~K}\left(300\right.$ and $375^{\circ} \mathrm{C}$ ) in air for $20.7 \mathrm{Ms}$ (8 months). In spite of a colossal supersaturation with carbon, the austenite does not precipitate carbides. No carbon is lost to the ambient. Carbon diffuses deeper into the alloy, resulting in a flatter carbon-fraction-depth profile. This is realistically simulated assuming temperature- and concentration-dependent carbon diffusion. Exposing to $648 \mathrm{~K}$ for $20.7 \mathrm{Ms}$ about doubles the average carbon depth. The near-surface carbon fraction decreases only moderately, particularly as the material appears to assimilate carbon from the ambient. Accordingly, the beneficial effects of low-temperature carburization on mechanical properties and corrosion resistance are retained throughout such long-term heat exposure, implying corresponding service life of low-temperaturecarburized parts at temperatures below $650 \mathrm{~K}$.

\footnotetext{
* Corresponding author

Email address: frank.ernst@case.edu
} 
Keywords: Low-temperature carburization, heat exposure, carbon diffusion, carbon-fraction-depth profiles, scanning Auger microprobe, hardness-depth profile.

\section{Introduction}

Austenitic stainless steels are highly resistant to corrosion. However, their surfacemechanical properties are less attractive [1]. Therefore, various methods have been employed to surface-harden these alloys [2]. One of the most effective methods is interstitial solid-solution hardening by carbon or nitrogen [2, 3]. The very low equilibrium solubility of carbon and nitrogen and the rapid increase of solubility with increasing temperature seem to suggest that the best strategy for obtaining high concentrations of interstitial solute is solute infusion at high temperature and subsequent quenching. However, such "conventional" carburizing and nitriding inevitably induce precipitation Cr-rich carbides or nitrides, which can have a very negative impact on mechanical properties (stress concentration) and corrosion resistance ("sensitization"). A much more potent approach, which has been developed over the past decades, is infusion of interstitial solute at low temperature. "Low," in this context, means a temperature at which the metal atoms of the alloy are practically immobile, thus incapable of precipitating with the solute, while the solute, since it resides in interstices between the metal atoms, can still diffuse over technically useful distances within technically feasible processing times. Under such "para-equilibrium" conditions [4], the concentrations of up to 15 at\% for carbon and 20 at\% for nitrogen can be infused and retained in solid solution. This corresponds to about $10^{5}$ times the equilibrium solubility limit, therefore constituting a "colossal supersaturation." It is well established that these high concentrations of interstitial solute are highly beneficial for mechanical properties (surface hardness, wear resistance, fatigue resistance) and corrosion resistance. This has found many applications, e.g. in nuclear reactors or chemical plants $[5,6]$.

Thermodynamically, a colossal supersaturation with interstitial solute leaves the alloy in an unstable (not "metastable") state, since at supersaturations of order $10^{5}$, nucleation barriers for precipitation will be small compared to the typical energy $k_{\mathrm{B}} T$ of thermal 
fluctuations ( $k_{\mathrm{B}}$ : Boltzmann constant, $T$ : absolute temperature). Particularly for applications at elevated temperature, therefore, it is highly important how the case and the related alloy properties respond to heat exposure. For a number of low-temperaturecarburized and -nitrided austenitic alloys, tests at elevated temperature have been carried out to determine their stability against carbide- or nitride precipitation [7-11]. The results were organized in the form of $\pi T$ (time-temperature-transformation) diagrams [11]. The strong temperature dependence of decomposition kinetics has led to the technically useful (if not physically exact) concept of a "threshold temperature" $[7-9,11-13]$, below which the case can be assumed to remain free of precipitates for a practically infinite lifetime.

However, even under conditions where precipitation can be neglected, the case may not be stable against redistribution of interstitial solute by diffusion or loss of solute to the ambient. For the example of low-temperature-carburized AISI-316L (austenitic stainless steel), therefore, we investigate the impact of long-term heat exposure on the carbon-AFDP (atom-fraction-depth profile).

\section{Experimental Methods and Procedures}

Table 1 compiles information on the specimens we studied in this work. "No-C" designates non-carburized, ordinary AISI-316L. "LT-C" designates the specimens in their initial state after LTC (low-temperature carburization), prior to the long-term heat exposure experiments. These specimens were "ferrules" made from AISI-316L and treated by LTC [3]. AISI-316L contains 18.5 at\% Cr, 11.6 at\% Ni, 2 at\% Mo, and balance Fe. LTC had been carried out by a gas-phase $\left(\mathrm{CO}, \mathrm{H}_{2}, \mathrm{~N}_{2}\right)$ process designed and carried out by the Swagelok Company [3, 14]. The long-term heat exposures were carried out in electric furnaces at 4 different temperatures (Table 1 ), all for the same time $t=20.7 \mathrm{Ms}$ ( 8 months). To characterize the material before and after temperature exposure, we employed a D8 diffractometer made by Bruker XRD (X-ray diffractometry) in Bragg-Brentano setting and with $\mathrm{Co}-\mathrm{K}_{\alpha}$ radiation. For metallographic analysis of the microstructure by LOM (light-optical microscopy), cross-sections of aged specimens were polished, chemically etched using a solution of $25 \mathrm{vol} \% \mathrm{HNO}_{3}, 50 \mathrm{vol} \% \mathrm{HCl}$, and 
25 vol\% $\mathrm{H}_{2} \mathrm{O}$. Hardness-depth profiles $h[z]$ were obtained from cross-sectional specimens by NHT (nano-hardness testing) using a G 200 nanoindenter, made by Keysight (formerly Agilent). The instrument operated with a load of $1 \mathrm{~g}$. In the non-hardened core of the AISI-316L specimens, this produced indents with a projected area of only $\approx 0.5 \mu \mathrm{m}^{2}$.

Carbon-AFDPs $X_{C}[z]$ were obtained by analyzing the cross-sectional specimens with a PHI 680 SAM (scanning Auger microprobe), made by Physical Electronics. In order to minimize artifacts introduced by adventitious carbon, we employed an established technique of continuous $\mathrm{Ar}^{+}$sputtering $[15,16]$. For precise quantification of the carbon concentration as a function of depth $z$ below the surface, we evaluated the measurements using standard data obtained from specimens with certified carbon concentrations $[15,16]$. For concentration-depth profiling determined by SAM, the effect of noise in the contributing Auger-electron energy spectra deserves particular attention. Evaluation of the carbon peak intensity involves differentiation of the spectra and evaluation of the maximum-minimum difference in the region of the differentiated carbon peak. Even in the absence of carbon, spectral noise will produce a nonvanishing derivative and, therefore, an apparent carbon level in regions of vanishing carbon concentration (non-carburized alloy core). To eliminate related artifacts, the experimental data were corrected with a newly developed method for signal-dependent background subtraction [17]. The resulting analytical uncertainty is estimated to be $<1$ at\% in absolute carbon concentration.

\section{Results}

The cross-sectional LOM micrograph in Fig la shows the microstructure of HT-4. Owing to higher corrosion resistance against metallographic etching, the case (carbon-infused layer) layer appears "featureless." Carbide precipitates were not discovered in such images. Since the AFDP of carbon is smoothly graded and the resistance against the metallographic etchant requires a minimum carbon fraction (e.g. 5 at\%), the apparent case depth $\zeta_{\text {Lом }}$ i. e. the thickness of the featureless layer, may slightly underestimate the true case depth $\zeta$ (e.g. defined as depth where $X_{C}=1$ at\%). Corresponding LOM 
images were obtained from the other specimens listed in Table 1. Figure $1 \mathrm{~b}$ shows the measured $\zeta_{\text {LOM }}[T]$.

Figure 2 shows X-ray diffractograms acquired in the LT-C ("as carburized") state and after the long-term heat exposures (Table 1 ). In the displayed range of the diffraction angle $2 \theta$, the diffractograms exhibit the $\{111\}$ and $\{200\}$ peaks of the austenite. For reference, the figure also shows the corresponding $\{111\}$ and $\{200\}$ peak positions expected for No-C - indicated by vertical dashed lines with corresponding labels. (Their positions follow from the lattice parameter $a_{0}=0.3599 \mathrm{~nm}$ of as-machined, noncarburized AISI-316L ferrules as experimentally determined by XRD and Nelson-Riley correction [18].)

Generally, as interstitially dissolved carbon expands the interatomic distances between the metal atoms, $X_{C}>0$ increases the plane spacings of the austenite and shifts the $\{111\}$ and $\{200\}$ peak positions to $2 \theta$ values smaller than the corresponding positions of No-C. Thus, the more the peaks of the diffractograms are shifted to lower $2 \theta$ compared to the corresponding vertical dashed lines in Fig 2, the higher is the level of interstitially dissolved carbon. (The actual peak position and shape follow from the actual solute distribution $X_{C}[z]$ and the depth-dependence of the $X$-ray intensity $I[z]$ in the near-surface zone sampled by the X-rays). Compared to the diffractogram of non-carburized AISI-316L, the peak positions obtained from the as-received low-temperature-carburized are shifted to smaller Bragg angles $\theta_{B}$, owing to lattice parameter expansion caused by interstitially dissolved carbon [19]. For the heat-treated specimens, the peak shifts are less and anti-correlate with the treatment temperature $T$. This indicates correspondingly reduced average carbon concentrations in the $\approx 5 \mu \mathrm{m}$-thick layer below the specimen surface that is sampled by the X-rays: Upon heat exposure, the near-surface region loses carbon. The higher the heattreatment temperature $T$, the more carbon is lost from the sampled zone within the treatment time $t$. In earlier work, carbide precipitation was apparent from as additional peaks in corresponding X-ray diffractograms, particularly in the angular range between the $\{111\}$ and $\{200\}$ austenite peaks. Since such additional peaks are not observed in Fig.2, we conclude that the heat exposures did not cause significant 
carbide precipitation. If carbides are present, at all, we estimate their volume fraction below $5 \%$.

Figure 3 presents the carbon-AFDPs $X_{C}[z]$ of LT-C and HT-4. They were obtained by quantifying the carbon fraction from Auger-electron energy spectra acquired at every scan point using the procedure described in Section 2. The final profiles are shown as black points. These were obtained from the initial profiles (light grey points) by background subtraction with the method described in Section 2. For LT-C, $X_{C}[z=$ $0]=0.14 \pm 0.01$ - corresponding to $\approx 100,000$ times (!) the equilibrium solubility of carbon room temperature. The profile falls off towards the interior of the specimen and approaches the noise level at an apparent case depth $\zeta_{\text {SAM }} \approx 30 \mu \mathrm{m}$. The profile of HT-4 is flatter, but also deeper. It starts at $X_{C}[z=0]=0.11 \pm 0.01$ and exhibits an apparent case depth $\zeta_{\text {SAM }} \approx 50 \mu \mathrm{m}$. Figure $3 \mathrm{~b}$ compares the nanohardness profile $h[z]$ of HT-4 with that of LT-C. Near the surface ( $z=0$ ), LT-C displays $h=14 \mathrm{GPa}$. The hardness prior to LTC can be estimated from the average hardness in the non-carburized alloy core region included in the $h[z]$ graph of the as-carburized ferrules (LT-C). The corresponding level is shown as a horizontal line in Fig 3b, marked with "No-C."

Consistent with the $X_{C}[z]$ in Fig $3 b$, both profiles indicate greatest hardness at the specimen surface $(z=0)$. Similar to the carbon-AFDP, the $h[z]$ of HT-4 is flatter, but also deeper than that of LT-C. In particular, the heat exposure HT-4 has reduced the hardness near the surface from $h=14 \mathrm{GPa}$ to $h=12 \mathrm{GPa}$, while increasing the apparent case depth from $\zeta_{\mathrm{NHT}} \approx 25 \mu \mathrm{m}$ to $\zeta_{\mathrm{NHT}} \approx 50 \mu \mathrm{m}$.

\section{Discussion}

While the three measures of apparent case depth, $\zeta_{\mathrm{LOM}}, \zeta_{\mathrm{SAM}}$, and $\zeta_{\mathrm{NHT}}$ are physically different, they are reasonably consistent $( \pm 5 \mu \mathrm{m})$ under the conditions considered here. Accordingly, the threshold carbon concentration at which the material becomes etch-resistant is low enough for the case depth 弓 to provide a realistic estimate of the true case depth, which is likely most reliably (though not necessarily most accurately) represented by $\zeta_{\mathrm{NHT}}$. $\zeta_{\mathrm{SAM}}$, on the other 
hand, may be less reliable when the underlying AES (Auger electron spectrometry) data are impacted by spectral noise, which offsets the profiles towards higher carbon levels. Therefore, a reliable method of background subtraction, as applied in this work [17], is important. Figure $3 a$ indicates that in both specimens the maximum carbon fraction occurs at the specimen surface $(z=0)$. This means that no carbon is lost to the exterior - in that case, where carbon diffuses outward (as well as inward), the law of diffusion would cause the regions closer to the surface to lose carbon more rapidly than regions deeper in the alloy, and a maximum of HT-4's $X_{C}[z]$ would be observed at some finite depth $z>0$ below the surface. The absence of carbon loss to the ambient is not trivial. For example, low-temperature-carbirized IN-718 (Ni-base superalloy), when exposed to higher heat-treatment temperatures, actually exhibits carbon loss to the exterior, which manifests itself as a decrease of $X_{C}[z]$ near the surface, such that $X_{C}[0]=0$ and the maximum of $X_{C}$ resides at a finite depth of about $5 \mu \mathrm{m}$ [20].

For the non-carburized core of LT-C, Fig $3 b$ indicates an average hardness of $\approx 5 \mathrm{GPa}$. That this value is higher than typical hardness levels quoted for AISI-316L appears to be a result of the machining by which ferrules are produced. While there is scatter in the hardness data, it appears that the plateau of HT-4 on the right-hand side of Fig $3 \mathrm{~b}$ is somewhat lower than the plateau of LT-C (5.1 GPa vs 5.3 GPa). Apparently, the long-term heat treatment somewhat softened the non-carburized core of the alloy by recovery.

The shape of both $X_{C}[z]$ profiles differs significantly from that of a complementary error function as it would be expected from Fick's second law (concentration-independent diffusion coefficient). The reason for the "concave" shape $\left(z_{2}>z_{1} \Rightarrow X_{C}\left[(1-v) z_{1}+\right.\right.$ $\left.v z_{2}\right]>(1-v) X_{C}\left[z_{1}\right]+v X_{C}\left[z_{2}\right]$ for $\left.0 \leq v \leq 1, v \in \mathbb{R}\right)$ observed here in regions $\left[z_{1}, z_{2}\right]$ of high $X_{C}$ is the strong increase of the carbon diffusion coefficient with increasing local carbon concentration [21]. While the $h[z]$ of Fig $3 b$ are correlated with the $X_{C}[z]$, their shapes are different because the local hardness depends on the local carbon fraction in a complicated way, involving solid-solution hardening [22] and work hardening due to plastic deformation induced by relaxation of compressive biaxial stress [4]. While there is much scatter in such hardness data, it appears that the plateau of HT-4 on the 
right-hand side of Fig $3 \mathrm{~b}$ is somewhat lower than the plateau of LT-C. This is expected as heat exposure enables recovery of the non-carburized core region of the alloy.

The evolution of LT-C'S AFDP of carbon into that of HT-4 (Fig 3a was modeled using two newly developed $\mathrm{C}++$ programs (extending earlier work) $[21,23,24]$ for BoltzmanMatano analysis [21] and numerical modeling of concentration-dependent diffusion. Details are described in the Appendix. Boltzman-Matano analysis of LT-C's $X_{C}[z]$ suggests that the concentration-dependence of the carbon diffusion coefficient can be realistically modeled in the following form [21]:

$$
D\left[X_{\mathrm{C}}, T\right]=D_{0} \operatorname{Exp}\left[-\frac{Q_{0}+\lambda X_{\mathrm{C}}}{k_{\mathrm{B}} T}\right],
$$

where $D_{0}$ is the "pre-factor" of the diffusion coefficient, $Q_{0}$ the activation energy of diffusion, $k_{\mathrm{B}}$ the Boltzmann constant, $T$ the temperature, and $\lambda$ a factor that characterizes the fraction- (or concentration-) dependence of the diffusion coefficient.

Figure $4 a$ presents a sequence of simulated carbon-AFDPs that were obtained in two steps: (i) Numerically fitting a Bézier curve ("LT-C") to the experimental data of LT-C in Fig $3 a$ and determining $D_{0}, Q_{0}$, and $\lambda$ in (1) by Boltzman-Matano analysis [21]. The results are indicated in the plot. (ii) Simulating concentration-dependent diffusion (1) with the parameter values determined in the first step. The simulation reproduces the experimentally observed flattening and increased depth of $X_{C}[z]$. The inset at the top right of Fig 4a shows the MDS (mean of the squared displacement) of the simulated profiles as a function of time $t$. Accordingly, HT-4 increases the initial MDS of LT-C by a factor of 4 . As much as the line connecting the data points is straight (it is not perfectly straight), the usual rule that the MDS is proportional to diffusion time applies to the added depth of carbon in the specimen. The inset also shows the MD (mean displacement - or mean depth) of carbon as a function of time $t$. Within the simulated time of $20.7 \mathrm{Ms}$, the MD increases by a factor of 2 .

Figure $4 \mathrm{~b}$ shows a comparison of the experimental data of Fig $3 a$ with the profile fit "LT-C" and the simulated $X_{C}[z]$ of HT-4 in Fig $4 a$. The simulation reproduces the experimentally observed flattening of the profile, the reduced carbon fraction at the surface $(z=0)$, and the increased case depth $\zeta$. However, the experimentally observed 
carbon fraction at the surface is higher than predicted. In fact, the integrated carbon fraction

$$
\int_{0}^{\infty} x_{C}[z] \mathrm{d} z=: \xi
$$

of HT-4 $(2.79 \mu \mathrm{m})$ is $9 \%$ greater than that of LT-C $(2.57 \mu \mathrm{m})$. While this could be an unidentified artifact of SAM, it is also possible that the specimen exposed to LT-4 has in fact assimilated carbon from the ambient. Indeed, the experimental $X_{C}[z]$ of HT-4 in Fig $4 \mathrm{~b}$ features a negative slope $\mathrm{d} X / \mathrm{d} z<0$ at $z=0$, indicating ongoing ingression of carbon. The simulated profiles in Fig $4 \mathrm{a}$, in contrast, exhibit vanishing slope $\mathrm{d} X / \mathrm{d} z=0$ at $z=0$, as expected for a surface through which carbon transport does not occur. An obvious source of carbon could be the $\mathrm{CO}_{2}$ (carbon dioxide) in the air. While $\mathrm{CO}_{2}$ is a very stable molecule, the thermodynamic data of Table 1 indicate that $\mathrm{CO}_{2}$ decomposition at $648 \mathrm{~K}$ is exothermic if the carbon atom is accepted in an environment energetically comparable to $\mathrm{Cr}_{23} \mathrm{C}_{6}$ and the oxygen atoms are incorporated in an Fe- or $\mathrm{Cr}$ oxide. Carburization of austenitic stainless steel by uptake of carbon from ambient $\mathrm{CO}_{2}$ has been observed earlier for 20/25-Nb alloys, althoug at higher temperatures (around 900 to $1000 \mathrm{~K}$ ) [25]. In fact, an equivalent reaction constitutes a major technical challenge for turbines operating with supercritical $\mathrm{CO}_{2}$, where it is found that the $\mathrm{CO}_{2}$ oxidizes and carburizes the turbine blades made from Cr-containing alloys [26]. Similarly, adsorption of $\mathrm{CO}_{2}$ on the surface of Zircaloy-4 is known to cause dissociation of the $\mathrm{CO}_{2}$ by formation of surface oxide and carbidic carbon [27]. Further, the hypothesis of $\mathrm{CO}_{2}$ decomposition enabled by metal-oxide formation explains the dark surface scale we observed forming on the HT-4 treated ferrule. The observed $9 \%$ increase in carbon content corresponds to the $\mathrm{CO}_{2}$ contained in a layer of air with a thickness of $2 \mathrm{~m}$. Considering the likely exchange of air in the ambient within the exposure time of $20.7 \mathrm{Ms}$, i. e. 8 months, the availability of carbon from $\mathrm{CO}_{2}$ in the ambient air suffices to explain the observed uptake of carbon.

\section{Conclusions}

Important for the service life of low-temperature-carburized AISI-316L, the results of this work demonstrate that long-term (20 Ms) exposure to temperatures up to $650 \mathrm{~K}$ does 
not cause significant carbide precipitation and only moderate degradation of properties. The most aggressive heat exposure of this study, $20.7 \mathrm{Ms}(8 \mathrm{months})$ at $648 \mathrm{~K}\left(375^{\circ} \mathrm{C}\right)$, increases the mean depth of the carbon atoms present in the "as-carburized" state by a factor of 2 and reduces the carbon fraction at the alloy surface to $\approx 2 / 3$ of the original value. Since no carbon is lost to the ambient (air), the main effect of heat exposure is further inward diffusion of the carbon that low-temperature carburization dissolved in the near-surface layer of the alloy. The resulting evolution of the carbon AFDP (atomfraction-depth profile), including flattening and depth increase, can be realistically simulated assuming concentration-dependent carbon diffusivity, confirming the validity of such calculations for quantitative predictions. In addition to inward diffusion of the carbon dissolved during LTC, the alloy with the strongest heat-exposure in air exhibits additional carbon within a zone adjacent to the surface: The integral of the AFDP of carbon increases by $\approx 10 \%$, indicating that heat-exposure in air enables carbon assimilation of from the ambient - apparently from the $\mathrm{CO}_{2}$ contained in the ambient air. This should actually be beneficial for the alloy properties and mitigate performance degradation by ongoing inward diffusion of carbon. In fact, the loss of surface hardness during the applied heat exposures is not dramatic, indicating a considerable service life of low-temperature-carburized AISI-316L for applications at temperatures below $650 \mathrm{~K}$.

\section{Acknowledgment}

This material is based upon work supported by the National Science Foundation under Grant No DMR-1208812. J Wang is very grateful for a grant of the China Scholarship Council (201206245098), a grant from the National Natural Science Foundation of China (No 51471112), and to Prof A H Heuer at Case Western Reserve University, USA, for financial support of this research. We thank P Williams, Swagelok Company, USA, for specimens and HDong at University of Birmingham, UK valuable discussions during research and writing. 


\section{Appendix}

The simulations employed in this work were carried out using two computer programs, BMA and CPE (F Ernst, unpublished). Both programs are coded in $\mathrm{C}++-11$ and were developed under XCode on the Macintosh OS X platform.

BMA performs Boltzmann-Matano analysis on experimentally determined atom-fractiondepth profiles, i. e. the diffusion coefficient as a function of local (carbon or other solute) atom fraction $X[z]$. This requires (i) integration over and (ii) differentiation of the inverse $z[X]$ of the experimental atom-fraction-depth profile $X[z]$. This, in turn, $X[z]$ to be a monotonous function, i. e. $z_{2}>z_{1} \Longrightarrow X\left[z_{2}\right]<X\left[z_{1}\right]$. To obtain a noise-reduced monotonous representation of the experimentally determined $X[z]$, BMA performs least-square fitting of a monotonous 4-point Bézier curve to the experimental data (8 parameters, 5 of which are independent). Once the parameters of the Bézier curve are determined, BMA performs numerical inversion, differentiation, and integration to determine $D[X]$.

CPE performs numerical simulation of atom-fraction- (concentration-) dependent diffusion, i. e. with a diffusion coefficient $D=D[X]$. Numerical differentiation is carried out by the "finite difference" method [28]. CPE provides great flexibility by allowing for an initial profile $X[z]$ to be provided for computing the further temporal evolution and alloying for time-dependence of temperature, surface transparency, and solute activity in the gas phase to be included.

BMA and CPE have been checked for self-consistency: A given diffusion profile $X[z]$ is properly reproduced by running CPE with the concentration dependence $D[X]$ determined by BMA. 


\section{References}

[1] P. Schaaf, Laser nitriding of metals, Progress in Materials Science 47 (1) (2002) $1-161$.

[2] A. Kosmač, Surface Hardening of Stainless Steels, Materials and Applications Series 20 (2015) 1-17.

[3] S. R. Collins, P. C. Williams, S. V. Marx, A. H. Heuer, F. Ernst, H. Kahn, LowTemperature Carburization of Austenitic Stainless Steels, in: J. Dossett, G. Totten (Eds.), ASM Handbook: Vol. 4D, Heat Treating of Irons and Steels, Vol. 4, ASM International, Materials Park, Ohio, 2014, pp. 451-460.

[4] G. M. Michal, F. Ernst, H. Kahn, Y. Cao, F. Oba, N. Agarwal, A. H. Heuer, Colossal Carbon Supersaturation due to Paraequilibrium Carburization: Stainless Steels with Greatly Improved Mechanical Properties, Acta Materialia 54 (2006) 15971606.

[5] J. P. Lebrun, L. Poirier, D. Hertz, C. Lincot, Environmentally friendly low temperature plasma processing of stainless steel components for nuclear industry, Surface Engineering 18 (6) (2002) 423-428.

[6] D. Hertz, Approach to analysis of wear mechanisms in the case of RCCAs and CRDM latch arms: From observation to understanding, Wear 261 (9) (2006) 1024-1031.

[7] X. Y. Li, Y. Sun, T. Bell, The stability of the nitrogen S-phase in austenitic stainless steel, Zeitschrift für Metallkunde 90 (11) (1999) 901-907.

[8] X. Y. Li, S. Thaiwatthana, H. Dong, T. Bell, Thermal stability of carbon S phase in 316 stainless steel, Surface Engineering 18 (6) (2002) 448-452.

[9] X. Y. Li, H. Dong, Effect of annealing on corrosion behaviour of nitrogen S phase in austenitic stainless steel, Materials Science and Technology 19 (10) (2003) 1427-1434.

[10] T. Christiansen, M. a. J. Somers, Decomposition kinetics of expanded austenite with high nitrogen contents, Zeitschrift für Metallkunde 97 (1) (2006) 79-88. 
[11] H. Dong, S-phase Surface Engineering of $\mathrm{Fe}-\mathrm{Cr}, \mathrm{Co}-\mathrm{Cr}$ and $\mathrm{Ni}-\mathrm{Cr}$ Alloys, International Materials Reviews 55 (2010) 65-98.

[12] E. Menthe, K. Rie, J. Schultze, S. Simson, Structure and Properties of PlasmaNitrided Stainless-Steel, Surface \& Coatings Technology 74-5 (1-3) (1995) 412416.

[13] O. Ozturk, D. L. Williamson, Thermal stability of the high-N solid-solution layer on stainless steel, Surface \& Coatings Technology 158 (2002) 288-294.

[14] P. C. Williams, S. R. Collins, Mechanical design using low-temperature carburization, Jom 60 (12) (2008) 27-30.

[15] A. Avishai, D. Isheim, D. N. Seidman, F. Ernst, G. M. Michal, A. H. Heuer, LocalElectrode Atom Probe (LEAP ${ }^{T M}$ ) Tomographic Microanalysis of Low-Temperature Gas-Carburized Austenitic Stainless Steel, Microscopy \& Microanalysis 13 Suppl. 2 (2007) 1094-1095.

[16] D. Wu, H. Kahn, G. M. Michal, F. Ernst, A. H. Heuer, Orientation Dependence of Nitrogen Supersaturation in Austenitic Stainless Steel During Low-Temperature Gas-Phase Nitriding, Acta Materialia 79 (2014) 339-350.

[17] F. Ernst, Background of SAM Atom-Fraction Profiles, Materials Characterization (2017) in press.

[18] H. W. King, E. A. Payzant, Error corrections for x-ray powder diffractometry, Canandan Metallurgical Quaterly 40 (2001) 385-394.

[19] Y. Cao, F. Ernst, G. M. Michal, Colossal Carbon Supersaturation in Austenitic Stainless Steels Carburized at Low Temperature, Acta Materialia 51 (2003) 41714181.

[20] Z. Li, Surface Hardening of Austenitic Fe-Cr-Ni Alloys for Accident-Tolerant Nuclear Fuel Cladding, PhD Thesis, Case Western Reserve University (2016).

[21] F. Ernst, A. Avishai, H. Kahn, X. Gu, G. M. Michal, A. H. Heuer, Enhanced Carbon Diffusion in Austenitic Stainless Steel Carburized at Low Temperature, Metallurgical and Materials Transactions A 40 (2009) 1768-1780. 
[22] R. Labusch, A Statistical Theory of Solid Solution Hardening, Physica Status Solidi 41 (1970) 659-669.

[23] X. Gu, G. M. Michal, F. Ernst, H. Kahn, A. H. Heuer, Concentration Dependence of Carbon Diffusivity in Austenite, Metallurgical and Materials Transactions A 45A (2014) 3790-3799.

[24] X. Gu, G. M. Michal, F. Ernst, H. Kahn, A. Heuer, Numerical Simulations of Carbon and Nitrogen Composition-Depth Profiles in Nitrocarburized Austenitic Stainless Steels, Metallurgical and Materials Transactions 45A (2014) 4268-4279.

[25] W. B. Jepson, J. E. Antill, J. B. Warburton, The oxidation and carburisation of a $20 / 25 / \mathrm{nb}$ steel in carbon dioxide, in carbon monoxide and in carbon dioxide-carbon monoxide mixtures, British Corrosion Journal (1965) 15-25.

[26] S. Kung, J. Shingledecker, D. Thimsen, I. Wright, B. Tossey, A. Sabau, Oxidation/Corrosion in Materials for Supercritical $\mathrm{CO}_{2}$ Power Cycles, in: 5th International Symposium on Supercritical $\mathrm{CO}_{2}$ Power Cycles, San Antonio, TX, 2016.

[27] N. Stojilovic, S. Farkas, R. Ramsier, Auger electron spectroscopic study of $\mathrm{CO}_{2}$ adsorption on Zircaloy-4 surfaces, Applied Surface Science 258 (2008) 2866-2870.

[28] M. N. Özisik, Finite Difference Methods in Heat Transfer, CRC Press, Inc., Boca Raton, FL 33431, USA, 1994. 


\section{Figure Legends}

1. Case depth in low-temperature-carburized AISI-316L as a function of exposure to temperature. (a) Cross-sectional light-optical micrograph, showing the microstructure and apparent case depth of HT-4. (b) Apparent case depth $\zeta_{\text {LOM }}$ in LT-C ("as-carburized") condition and after the heat treatments of Table 1.

2. X-ray diffractograms of low-temperature-carburized AISI-316L in the conditions shown in Table 1 . The $\{111\}$ and $\{200\}$ peak positions expected for No-C (non-carburized AISI-316L ferrules) are indicated by vertical dashed lines with corresponding markers.

3. Effect of heat treatment on carbon distribution and hardness. (a) Carbon-AFDPs $X_{C}[z]$ in LT-C ("as-carburized") condition and after heat treatment HT-4, obtained by SAM. (b) Corresponding hardness-depth profiles $h[z]$, measured by nanoindentation. "No-C" indicates the approximate average hardness of the non-carburized alloy core region of the as-carburized ferrules (LT-C).

4. Temporal evolution of the AFDP of carbon upon heat exposure to $T_{4}=648 \mathrm{~K}$. (a) Numerical simulation for time interval $[0,20.7]$ Ms. "LT-C" is a Bézier curve numerically fitted to the experimentally obtained $X_{C}[z]$ of LT-C. The other graphs represent the temporal evolution of the profile in equidistant time steps, simulated with the parameters given at the top right. The bold line is $X_{C}[z]$ of HT-4, after $t=20.7 \mathrm{Ms}$. The inset at the top right shows the MDS of the simulated profiles. (b) Comparison with the experimental data of Fig $3 a$. 

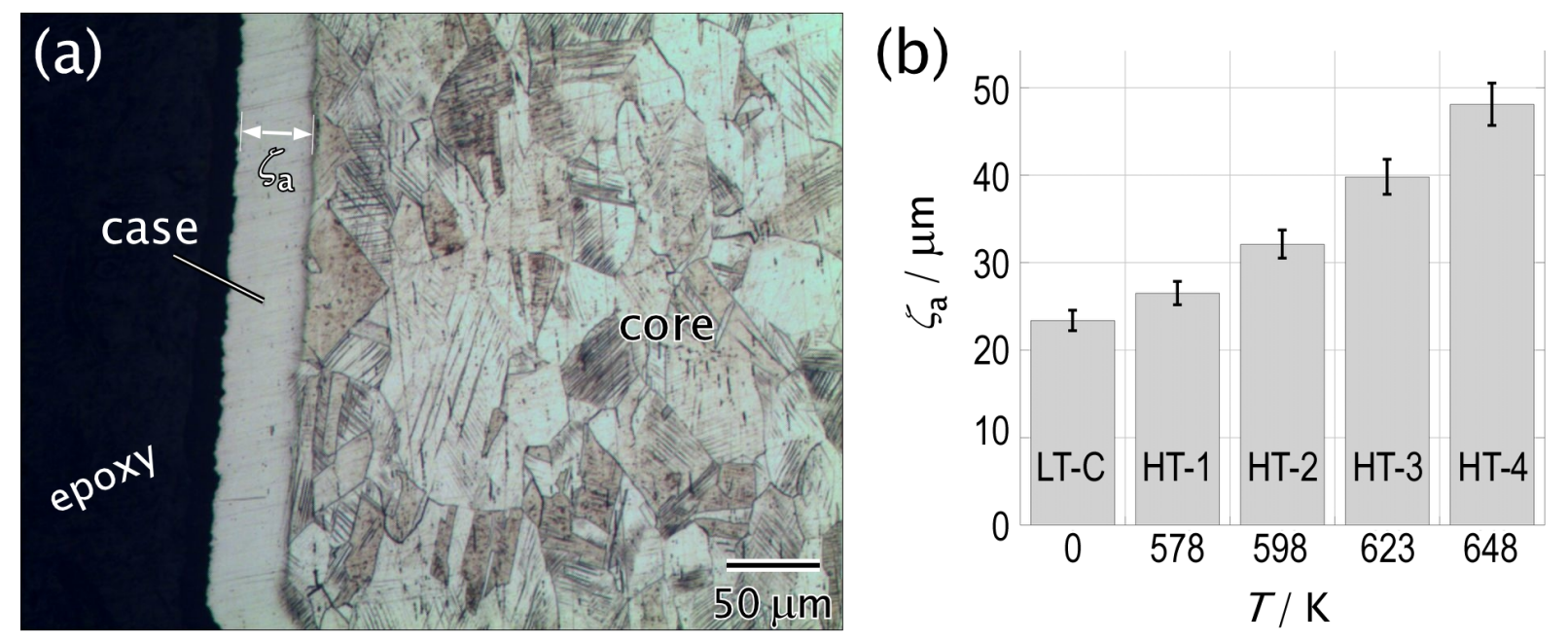

Figure 1: Case depth in low-temperature-carburized AISI-316L as a function of exposure to temperature.

(a) Cross-sectional light-optical micrograph, showing the microstructure and apparent case depth of HT-4.

(b) Apparent case depth $\zeta_{\text {LOM }}$ in LT-C ("as-carburized") condition and after the heat treatments of Table 1. 


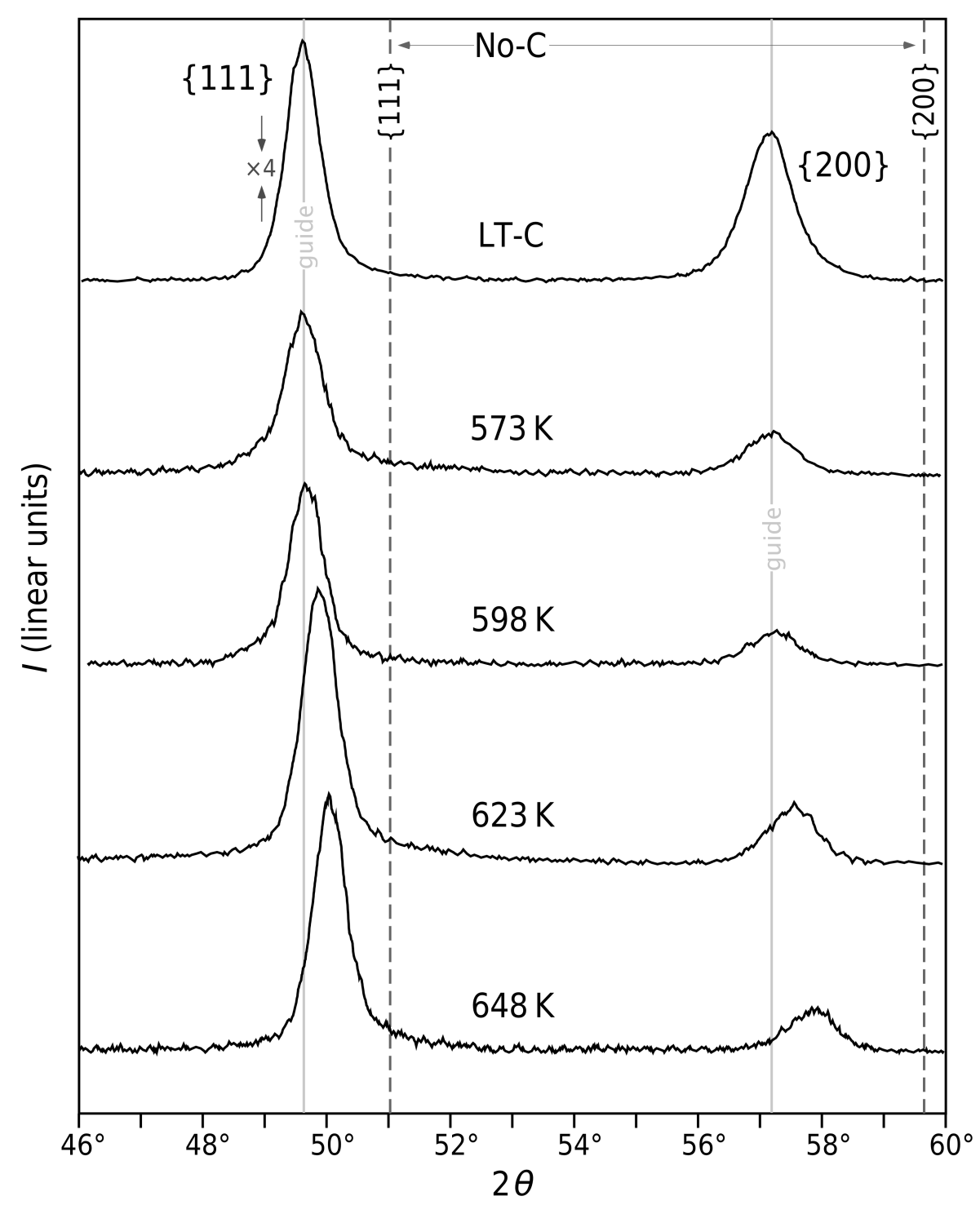

Figure 2: X-ray diffractograms of low-temperature-carburized AISI-316L in the conditions shown in Table 1. The $\{111\}$ and $\{200\}$ peak positions expected for No-C (non-carburized AISI-316L ferrules) are indicated by vertical dashed lines with corresponding markers. 
(a)

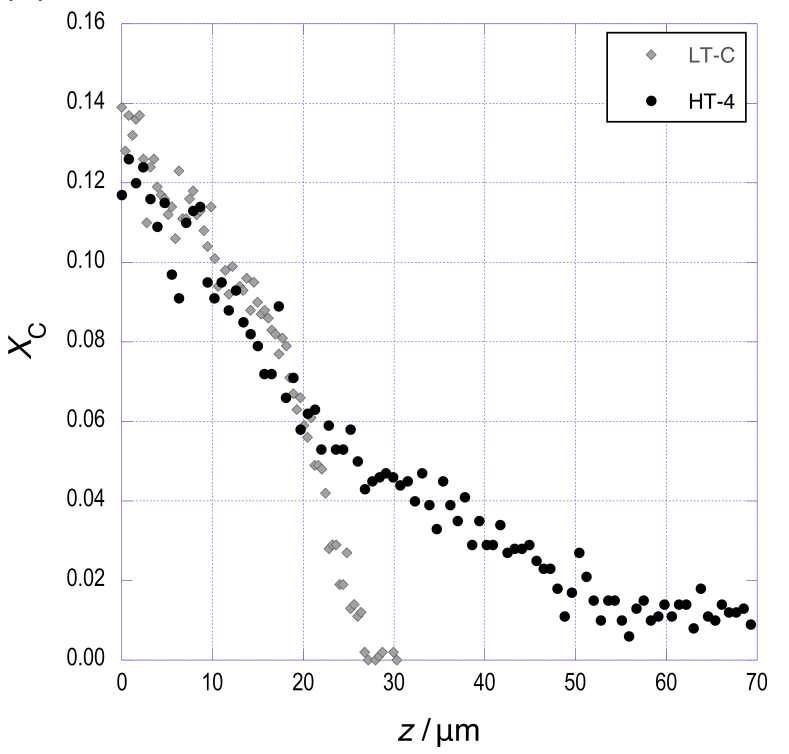

(b)

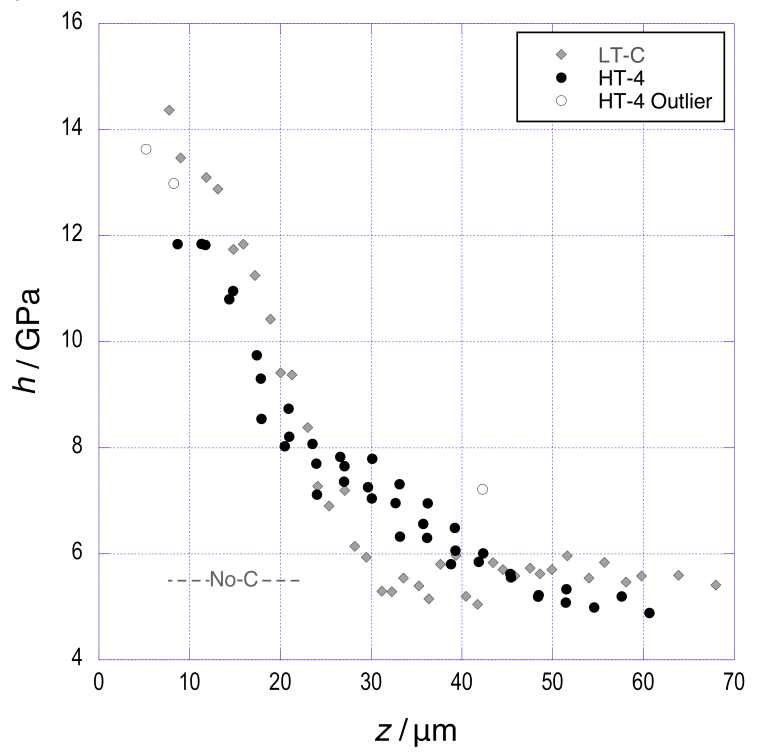

Figure 3: Effect of heat treatment on carbon distribution and hardness. (a) Carbon-AFDPs $X_{C}[z]$ in LT-C ("as-carburized") condition and after heat treatment HT-4, obtained by SAM. (b) Corresponding hardness-depth profiles $h[z]$, measured by nanoindentation. "No-C" indicates the approximate average hardness of the non-carburized alloy core region of the as-carburized ferrules (LT-C). 

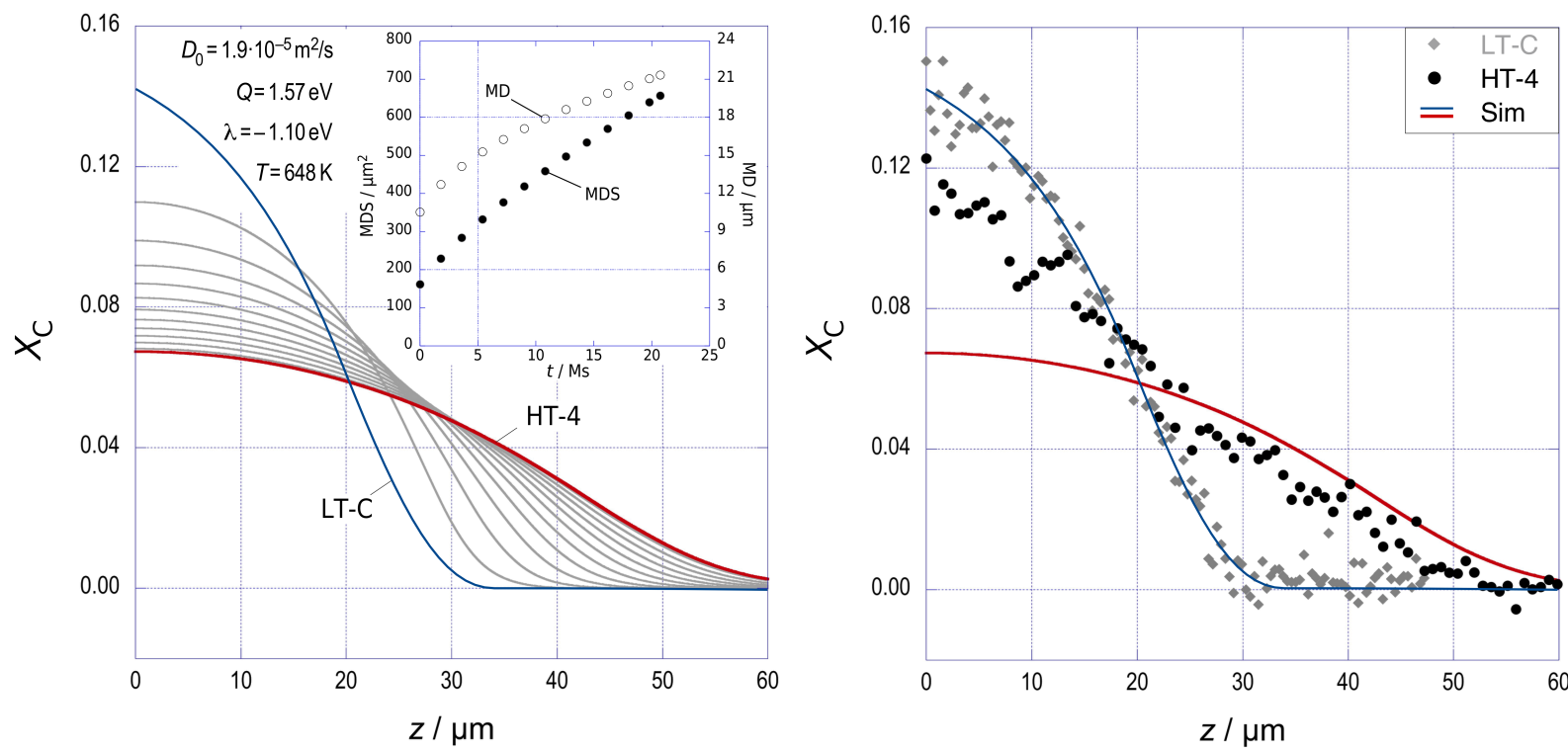

Figure 4: Temporal evolution of the AFDP of carbon upon heat exposure to $T_{4}=648 \mathrm{~K}$. (a) Numerical simulation for time interval $[0,20.7] \mathrm{Ms}$. "LT-C" is a Bézier curve numerically fitted to the experimentally obtained $X_{C}[z]$ of LT-C. The other graphs represent the temporal evolution of the profile in equidistant time steps, simulated with the parameters given at the top right. The bold line is $X_{C}[z]$ of HT-4, after $t=20.7 \mathrm{Ms}$. The inset at the top right shows the MDS of the simulated profiles. (b) Comparison with the experimental data of Fig 3a. 


\section{Tables}

Table 1: Specimens

\begin{tabular}{|c|c|c|}
\hline ID & $\begin{array}{c}\text { Temperature } \\
T\end{array}$ & $\begin{array}{c}\text { Time } \\
t\end{array}$ \\
\hline No-C & - & - \\
\hline LT-C & - & - \\
\hline HT-1 & $\begin{array}{c}T_{1}=573 \mathrm{~K} \\
300^{\circ} \mathrm{C}\end{array}$ & \multirow{4}{*}{$t_{1}=20.7 \mathrm{Ms}$} \\
\hline HT-2 & $\begin{array}{c}T_{2}=598 \mathrm{~K} \\
325^{\circ} \mathrm{C}\end{array}$ & \\
\hline HT-3 & $\begin{array}{c}T_{3}=623 \mathrm{~K} \\
350^{\circ} \mathrm{C}\end{array}$ & \\
\hline HT-4 & $\begin{array}{c}T_{4}=648 \mathrm{~K} \\
375^{\circ} \mathrm{C}\end{array}$ & \\
\hline
\end{tabular}


Table 2: Thermodynamic Data

\begin{tabular}{|c|c|c|}
\hline Reagents & Products & $\Delta G(\mathrm{MJ} / \mathrm{mol})$ \\
\hline $23 \mathrm{Cr}+9 \mathrm{Fe}+6 \mathrm{CO}_{2}$ & $\mathrm{Cr}_{23} \mathrm{C}_{6}+3 \mathrm{Fe}_{3} \mathrm{O}_{4}$ & -0.67 \\
$23 \mathrm{Cr}+8 \mathrm{Fe}+6 \mathrm{CO}_{2}$ & $\mathrm{Cr}_{23} \mathrm{C}_{6}+4 \mathrm{Fe}_{2} \mathrm{O}_{3}$ & -0.58 \\
$23 \mathrm{Cr}+12 \mathrm{Fe}+6 \mathrm{CO}_{2}$ & $\mathrm{Cr}_{23} \mathrm{C}_{6}+12 \mathrm{FeO}$ & -0.69 \\
$23 \mathrm{Cr}+6 \mathrm{CO}_{2}$ & $\mathrm{Cr}_{23} \mathrm{C}_{6}+4 \mathrm{Cr}_{2} \mathrm{O}_{3}$ & -1.86 \\
$23 \mathrm{Cr}+6 \mathrm{CO}$ & $\mathrm{Cr}_{23} \mathrm{C}_{6}+3 \mathrm{O}_{2}$ & +0.64 \\
$23 \mathrm{Cr}+6 \mathrm{CO}+6 \mathrm{H}_{2}$ & $\mathrm{Cr}_{23} \mathrm{C}_{6}+6 \mathrm{H}_{2} \mathrm{O}$ & -1.13 \\
$8 \mathrm{Cr}+6 \mathrm{O}_{2}$ & $4 \mathrm{Cr}_{2} \mathrm{O}_{3}$ & -3.88 \\
\hline
\end{tabular}


Thermal Stability of Low-Temperature Carburized Austenitic Stainless Steel

Low-Temperature Carburization

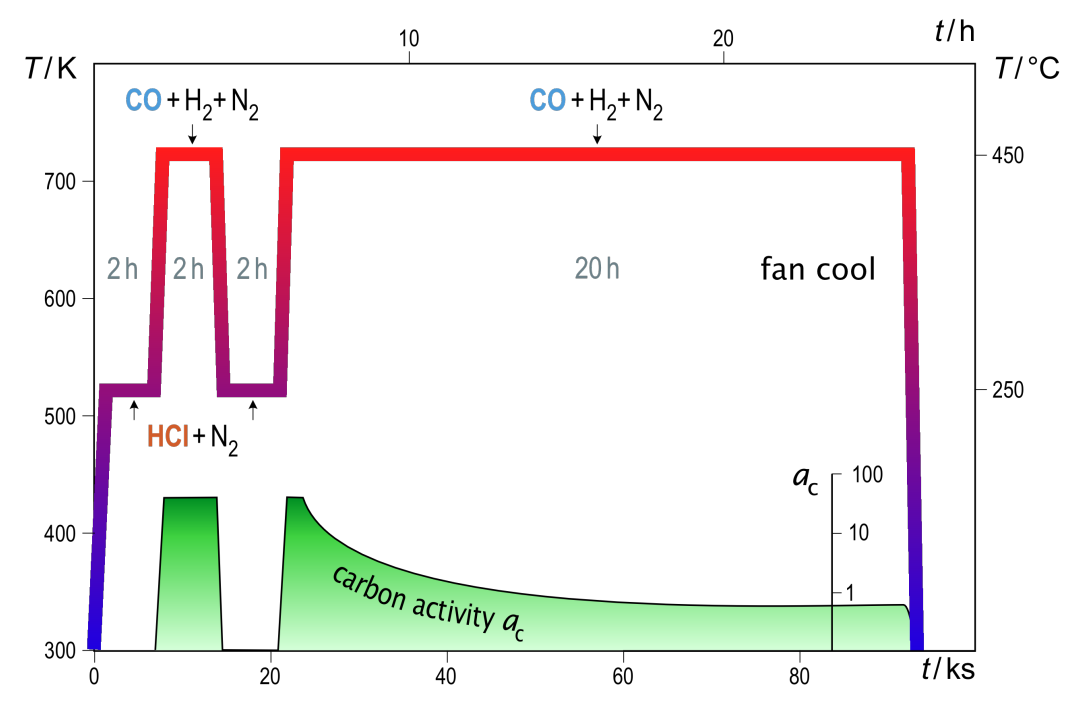

Carbon Atom-Fraction-Depth Profile

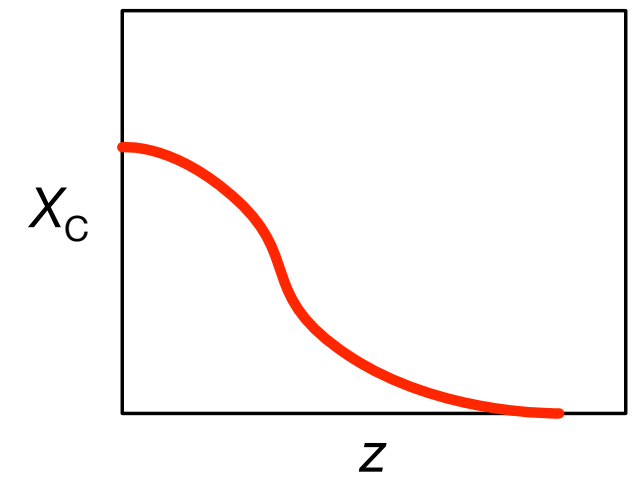

$316 \mathrm{~L}$

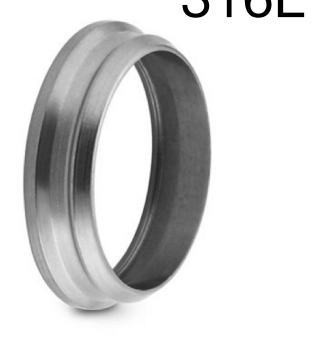

Heat Exposure in Air
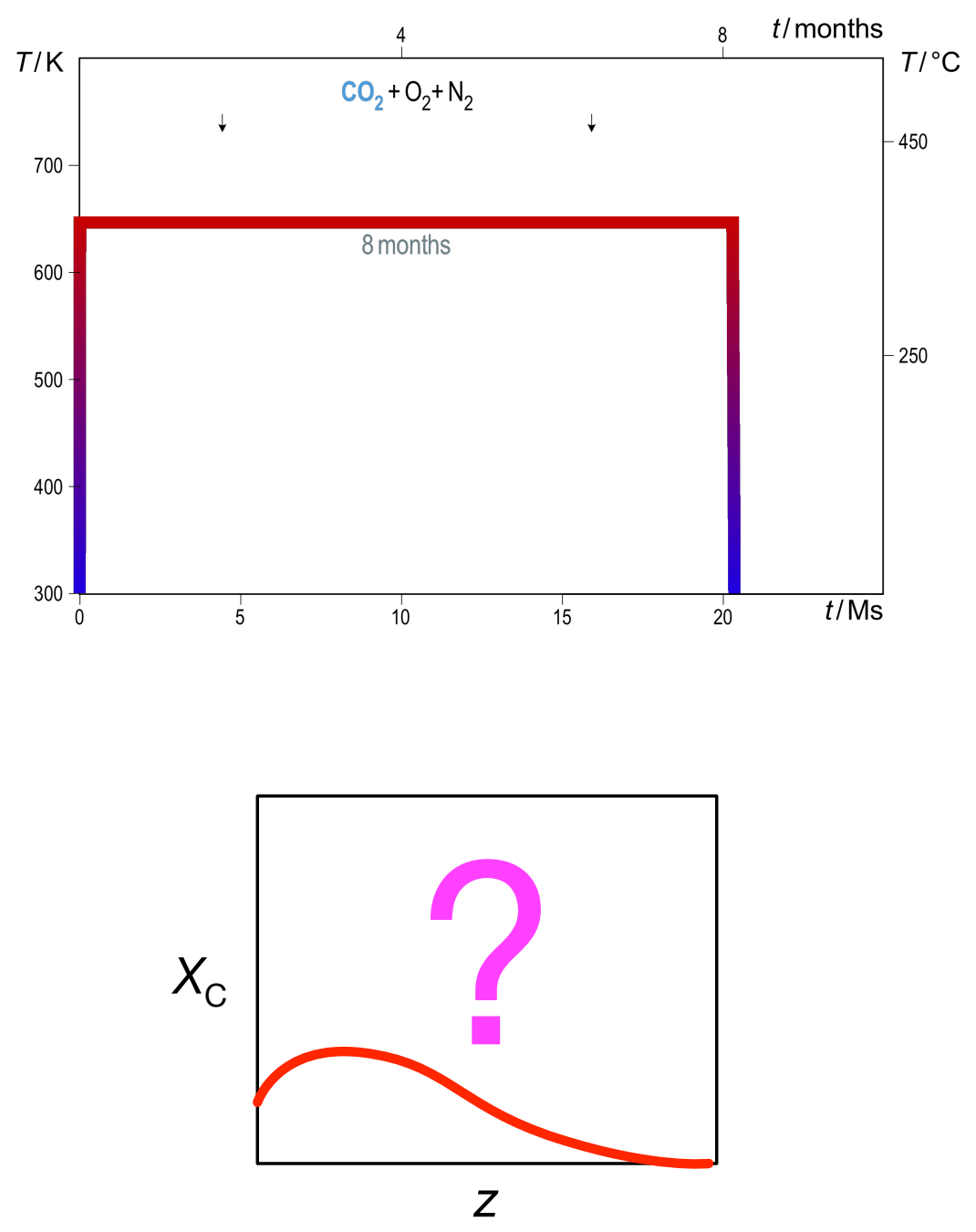